\title{
Zika Virus Infection and Implications for Reproduction
}

\author{
Michelle L. Giles ${ }^{1, \star}$, Stephen Cole ${ }^{2,3}$ \\ ${ }^{1}$ Department of Obstetrics and Gynaecology, Monash University, Melbourne, Australia \\ ${ }^{2}$ Department of Maternal-Fetal Medicine, The Royal Women's Hospital, Melbourne, Australia \\ ${ }^{3}$ Institute of Obstetrics and Gynaecology, Epworth Healthcare, Melbourne, Australia
}

\begin{abstract}
Zika virus infection during pregnancy can have devastating effects on the foetus leading to congenital Zika syndrome. It is relevant therefore for couples living in countries with endemic Zika virus to understand the strategies they can utilise to reduce the chance of infection. In addition, couples planning pregnancy, or who are already pregnant, travelling to countries with Zika virus need to be informed of the potential risk and implications for future reproductive planning.
\end{abstract}

Keywords: Zika Virus; Fertility; Reproduction; Pregnancy; Transmission; Testing.

\section{BACKGROUND}

Zika virus (ZIKV), although originally isolated in 1947, has only recently been recognized for its potential impact on pregnancy outcomes. The implications of ZIKV infection during pregnancy have emerged over the past three years primarily due to the epidemic in South America. Prior to this, human cases have been reported since 1952, including the first epidemic in Micronesia in 2007 (Duffy et al., 2009) and in 2013 an epidemic in French Polynesia (Cao-Lormeau et al., 2014), with few reported symptoms or sequelae at the time. Subsequently, after the reported cases of fetal abnormalities in South America, retrospective studies conducted in French Polynesia found an increase in congenital malformations in newborns during this period (Besnard et al., 2016; Cauchemez et al., 2016). In February 2016, the World Health Organization declared ZIKV infection a Public Health Emergency of International Concern, thereby mobilizing resources directed towards enhanced surveillance, development of new diagnostics, enhanced risk communications and vector control measures.

ZIKV was first isolated from a febrile Rhesus macaque in the Zika forest in Uganda in 1947 and then was subsequently found in the Aedes spp. mosquito in the same forest one year later (Dick et al., 1952). It is an arthropod-borne virus of the Flaviviridae family, closely related to other viruses such as Dengue virus and Yellow Fever. As of $4^{\text {th }}$ January 2018, the total number of cumulative autochthonous cases reported in the Americas totaled 585,451 confirmed and 223,477 suspected cases (Pan American Health Organization/World Health Organization, 2018). In addition, a total of 6329 imported cases in the Americas have been reported with an incidence rate of 80.41/100,000 population (Pan American Health Organization/ World Health Organization, 2018). A total of 3720 confirmed cases of congenital Zika syndrome have been reported in the Americas (Pan American Health Organization/World Health Organization, 2018).

\section{CONGENITAL ZIKA SYNDROME}

Congenital Zika Syndrome (CZS) comprises a constellation of recognized fetal/infant abnormalities (Moore et al., 2017; Mlakar et al., 2016; Walker et al., 2018). Affected fetuses and infants may display one or more of the known identifiable malformations. In the fetus, identifiable manifestations include: microcephaly (head circumference $<3^{\text {rd }}$ centile), cerebral abnormalities including cortical thinning with sub-cortical calcification, ventriculomegaly, lissencephaly, polymicrogyria, cerebellar hypoplasia and corpus callosum abnormalities, contractures (arthrogryposis), intrauterine growth restriction (IUGR), often with sparing of femora (Walker et al., 2018) and oligohydramnios. Fetal hydrops has also been reported (Sarno et al., 2016).

The rate of fetal/infant Zika infection has been reported to be between 5\% (Shapiro-Mendoza et al., 2017) and 40\% (Brasil et al., 2016). Early reports were complicated by incomplete follow up of infants and possible selection bias. A more recent prospective study of confirmed maternal Zika infection in pregnancy demonstrated transmission in $26 \%$ of (76 of 291) neonates (Pomar et al., 2018). Of those neonates that tested positive for Zika at birth, $45 \%$ presented with no signs or complications at birth. Developmental delay at 12-18 months was identified in approximately $14 \%$ of children following confirmed maternal Zika infection in two studies but these were limited by incomplete follow-up (Rice et al., 2018; Moreira et al., 2018).

Diagnosis of a CZS in the fetus is based on a combination of clinical symptoms suggestive of maternal infection, laboratory confirmation of Zika infection, detection of Zika virus RNA on amniotic fluid from amniocentesis using polymerase chain reaction (PCR), and the identification of one or more fetal abnormalities as described above. As the clinical features of maternal Zika infection may be mild and non-specific, a high index of suspicion is required

() 2019 by the Asia Pacific Initiative on Reproduction (ASPIRE) and World Scientific Publishing Co. Pte. Ltd. O Open Access article under the CC BY-NC-ND license (http://creativecommons.org/licenses/by-nc-nd/4.0/).

Received 11 February 2019; Accepted 12 February 2019; Published 1 March 2019

${ }^{*}$ Correspondence should be addressed to: Associate Professor Michelle Giles, Infectious Diseases Unit, Alfred Hospital, Commercial Road, Prahran, VIC 3181, Australia. Email: m.giles@alfred.org.au 
when women or their sexual partners live in or have travelled to a Zika-affected region.

Whilst the presence of Zika RNA in amniotic fluid is highly specific, the sensitivity of this test has not been established. The optimal timing for amniocentesis is also not established. Small case series describe the timing of amniocentesis based on empiric estimates derived from the CMV literature - That is, at least 6 weeks post infection, and at least 21 weeks gestation (Shaub et al., 2017), although there are reports of positive amniotic fluid PCR from earlier gestations (Benjamin et al., 2017). It also appears that Zika RNA may not always be detected throughout the entire duration of pregnancy. Shaub and colleagues describe six cases where Zika RNA was initially detected in amniotic fluid using PCR, but was subsequently not detected at later repeat amniocentesis in two of the six cases (Shaub et al., 2017).

Ultrasound features of CZS may not be apparent initially, and are most commonly seen in the third trimester (Lovagnini Frutos et al., 2018; Sanz Cortes et al., 2018). Parra-Saavedra and colleagues report 17 cases of confirmed or presumed first trimester maternal Zika infection (7-14 weeks) with a mean duration from time of diagnosis to time of detection of microcephaly of 18 weeks (range 15-24 weeks) (Parra-Saavedra et al., 2017). In pregnancies where maternal Zika infection has been confirmed, serial ultrasounds are recommended, however the optimal timing of surveillance is not known (Oduyebo et al., 2017). MRI may be more sensitive at detecting structural brain changes (Goncalves et al., 2016), but again the optimal timing for MRI has not been established. In the absence of a confirmed diagnosis of viral RNA from amniotic fluid, the presence of one or more of the fetal features described above, in combination with maternal potential for exposure and supporting laboratory evidence of Zika infection, along with the exclusion of other causes should lead to a presumptive diagnosis of CZS.

Following diagnosis of CZS, parents should be counselled regarding the implications of the diagnosis. Currently there are no antenatal therapeutic interventions known to ameliorate the physical changes or long term sequelae of CZS. Parental requests for termination of pregnancy may be considered where cases comply with local laws and guidelines. Unfortunately ultrasound features of CZS may not become apparent until the third trimester, when termination of pregnancy may not be possible in many jurisdictions.

\section{HOW IS ZIKA VIRUS TRANSMITTED?}

ZIKV is predominantly transmitted via mosquitos. However, other non-vector routes of transmission have been reported including sexual transmission (McCarthy, 2016; D’Ortenzio et al., 2016), blood transfusion (Musso et al., 2014; Boadle et al., 2019), animal bite (Leung et al., 2015), and possibly breast milk (Blohm et al., 2018; Colt et al., 2017) and other bodily fluids (Swaminathan et al., 2016).

\section{SEXUAL TRANSMISSION AND EFFECT OF ZIKA VIRUS INFECTION ON THE REPRODUCTIVE TRACT}

Even though vector borne transmission remains the primary mode of transmission, sexual transmission is an important consideration for couples planning pregnancy. In 2017, a systematic review reported on 18 studies reporting person-person transmission of ZIKV through sexual transmission (Moreira et al., 2017). These studies included male-to-female transmission, male-to-male transmission and female-to-male transmission. Transmission has been reported when the sexual activity occurred before, during and after the index case symptom onset (Moreira et al., 2017). It remains unclear whether there is a significant difference in risk of transmission according to severity of symptomatic illness.

This systematic review also examined shedding of ZIKV in genital fluids (Moreira et al., 2017). Twenty-one studies reported on shedding of ZIKV, most of these studies were exploring shedding in male genital secretions (semen and seminal plasma). ZIKV was detected in semen up to 188 days after symptom onset in one study (Nicastri et al., 2016). However, many of these studies used nucleic acid detection for identifying ZIKV, rather than tests of virus viability. In those studies that assessed for viability by cell culture, the longest that replicative virus remained in semen was for 69 days after symptom onset (Arsuaga et al., 2016). Furthermore, sexual transmission to a female has been reported 44 days after the onset of symptoms in her partner (Turmel et al., 2016). In the systematic review by Moreira et al., all studies that explored detection time from other body compartments, reported that the duration of shedding in urine, serum, saliva and cerebrospinal fluid were much shorter than genital tract secretion samples (Moreira et al., 2017). In relation to the female genital tract, shedding is much shorter, reported up to 31 days after the onset of symptoms (da Cruz et al., 2019).

More recently, a prospective study of men with symptomatic ZIKV infection, were followed with urine and semen samples for up to 304 days after illness (Mead et al., 2018). In those in whom ZIKV RNA was detected in semen, $61 \%$ were detected within 30 days of infection, with shedding decreasing substantially thereafter. In one man (1\%), ZIKV was still detected 281 days after infection (Mead et al., 2018). On the basis of these results, it is estimated that only $5 \%$ of men would have detectable levels of ZIKV at 158 days after symptom onset (up to 186 days, 95\% confidence interval). Factors associated with a longer time to clearance of ZIKV RNA from semen included older age, presence of conjunctivitis at time of initial illness and less frequent ejaculation (Mead et al., 2018). In addition, intermittent shedding was reported, meaning that a single negative ZIKV RNA result in semen cannot rule out future shedding of the virus.

The long-term effect (if any) on testicular and reproductive function is still being determined. Studies have reported evidence of semen inflammation (Huits et al., 2016), prostatitis (Foy et al., 2011) and in animal studies persistent testicular damage (Ma et al., 2016). In 2017, Joguet and colleagues reported changes to sperm and testicular function in men infected with Zika virus (Joguet et al., 2017). In this study, 15 men were followed prospectively after acute ZIKV infection. Both quantitative and qualitative harmful effects on spermatozoa production were demonstrated (Joguet et al., 2017) with recovery by 120 days. This included a decrease in sperm count and concurrent increase in sperm abnormalities. Similarly, in mice models, Zika virus infection leads to inflammation of the epididymis, cell necrosis, and testicular atrophy (Griffin et al., 2017; Govero et al., 2016).

\section{IMPLICATIONS WHEN PLANNING PREGNANCY AND FERTILITY TREATMENT}

The presence of ZIKV alone in seminal plasma may not be sufficient to infect the ovum, zygote or morula. The zona pellucida, a glycoprotein layer around the zygote, may protect it from direct infection by ZIKV as it remains unknown if ZIKV can bind to the zona pellucida. After the ovum is fertilized by the spermatid, the zona pellucida degenerates and is replaced by a layer of trophoblastic cells.

Current recommendations produced by the Centers for Disease Control and Prevention highlight the importance of protecting oneself from getting mosquito bites by use of insect repellant, covering skin and mosquito-proofing the home (if residing in 
an Endemic area). These same principles apply for individuals travelling to Zika-infected countries who are planning pregnancy. Once pregnant, strategies to protect yourself from getting Zika from sex includes using a condom or avoiding sexual intercourse for the duration of the pregnancy.

In 2018, the Centers for Disease Control published updated interim guidance for preconception counseling and prevention of sexual transmission of ZIKV for men with possible ZIKV exposure changing the recommendation to wait six months down to three months (Polen et al., 2018). This was based on emerging evidence that at greater than 90 days after illness onset, less than $7 \%$ of men will have detectable ZIKV RNA in semen, with a mean time to clearance of 54 days (Mead et al., 2018).

If a female partner alone travels to an area where she may be at risk of Zika infection, current recommendations suggest waiting two months before conception, although there are no cases of congenital Zika infection in offspring born to women who were infected one month prior to conception.

If both male and female partners travel to an area where they may be infected with Zika, they should consider using condoms or avoid having sexual intercourse for at least three months after leaving the Zika affected area (Polen et al., 2018). One option to shorten this timeframe sometimes considered by clinicians, although not recommended in certain guidelines (Polen et al., 2018), is serological testing.

Diagnostic tests for ZIKV can be via molecular or serological methodology. Molecular testing to establish a diagnosis of infection may be employed in people who may have been exposed to Zika through sex and who have Zika virus symptoms, in pregnant women who have symptoms of Zika and have recent exposure to Zika, or for asymptomatic pregnant women with ongoing exposure to Zika. Molecular testing for ZIka infection is by nucleic acid testing (NAT) for RNA on blood or urine. The duration of viremia is short so a negative result may be falsely reassuring. Although molecular testing has been utilized on semen samples in a research setting, this has not been recommended to determine potential risk of sexually transmitting Zika virus.

Serological tests involve IgG and IgM antibody testing. If an antibody test is performed too early after infection, it may be falsely negative because insufficient time has elapsed since infection to produce a level of antibody detectable by the assay. And, like with many serological tests for other infectious diseases, IgM antibodies may persist for months to years. Serological testing for Zika infection is also complicated by cross-reactivity with other flaviviruses such as Dengue virus. In this scenario, further testing by plaque neutralization tests (PRNT) that measure virus-specific neutralizing antibodies may be necessary.

\section{RECOMMENDATIONS FOR COUPLES LIVING IN ENDEMIC AREAS}

For populations who reside in areas with endemic Zika, it is recommended that individuals planning pregnancy discuss with their healthcare provider their plans, the potential risk and implications of Zika infection during pregnancy, and strategies to reduce the risk of infection (Petersen et al., 2016).

\section{CONCLUSION}

Although human infection and sexual transmission with ZIKV was established decades ago, it was not until the outbreak in 2015 that the full spectrum of potential effects on the developing fetus began to be recognized. Since then, the causal role of ZIKV in the constellation of symptoms and signs of congenital Zika syndrome, most often neurological, has been established. As research and understanding of transmission risk increases at an exponential rate, it is important to remember the additional considerations this poses for couples who are either pregnant and at risk of Zika infection, or are planning a future pregnancy.

\section{REFERENCES}

Arsuaga M, Bujalance SG, Diaz-Menendez M, Vazquez A, Arribas JR. Probable sexual transmission of Zika virus from a vasectomized man. Lancet Infect Dis. 2016;16:1107.

Benjamin I, Fernandiz G, Figueira JV, Parpacen L, Urbina MT, Medina R. Zika virus detected in amniotic fluid and umbilical cord blood in an in vitro fertilization-conceived pregnancy in Venezuela. Fertil Steril. 2017;107(6):1319-22.

Besnard M, Eyrolle-Guignot D, Guillemette-Artur P, et al. Congenital cerebral malformations and dysfunction in fetuses and newborns following the 2013 to 2014 Zika virus epidemic in French Polynesia. Euro Surveill. 2016;21:13.

Blohm GM, Lednicky JA, Márquez M, et al. Evidence for mother-tochild transmission of Zika virus through breast milk. Clin Infect Dis. 2018;55:1120-1. https://doi.org/10.1093/cid/cix968External

Boadle A. Brazil reports Zika infection from blood transfusions. Reuters n.d. http://www.Reuters.com/article/us-health-zikabrazil-blood-idUSKCNOVD22N (Accessed Feb 1, 2019).

Brasil P, Pereira JP, Moneira E, et al. Zika virus infection in pregnant women in Rio de Janeiro. N Engl J Med. 2016;375:2321-34.

Cao-Lormeau VM, Roche C, Teissier A, et al. Zika virus, French Polynesia, South Pacific 2013. Emerg Infect Dis. 2014;20:1085-6.

Cauchemez S, Besnard M, Bompard P, et al. Association between Zika virus and microcephaly in French Polynesia 2013-15: A retrospective study. Lancet. 2016;387:2125-32.

Colt S, Garcia-Casal MN, Peña-Rosas JP, et al. Transmission of Zika virus through breast milk and other breastfeeding-related bodily fluids: A systematic review. PLoS Negl Trop Dis. 2017;11: e0005528. https://doi.org/10.1371/journal.pntd.0005528External

da Cruz TE, Souza RP, Pelloso SM, et al. Case reports: Prolonged detection of Zika virus RNA in vaginal and endocervical samples from a Brazilian woman, 2018. Am J Trop Med Hyg. 2019;100(1):183-6.

Dick GW, Kitchen SF, Haddow AJ. Zika virus: Isolations and serological specificity. Trans R Soc Trop Med Hyg. 1952;46:509-20.

D’Ortenzio E, Matheron S, Yazdanpanah Y, et al. Evidence of sexual transmission of Zika virus. N Engl J Med. 2016;374:2195-8.

Duffy M, Chen TH, Hancock T, et al. Zika virus outbreak on Yap Island, Federated States of Micronesia. N Engl J Med. 2009;360:2536-43.

Foy BD, Kobylinski KC, Chilson Foy JL, et al. Probable non-vectorborne transmission of Zika virus, Colorado USA. Emerg Infect Dis. 2011;17:880-2.

Goncalves LF, Lee W, Mody S, et al. Diagnostic accuracy of ultrasonography and magnetic resonance imaging for the detection of fetal anomalies: A blinded case-control study. Ultras Obstet Gynecol. 2016 Aug;48(2):185-92.

Govero J, Esakky P, Scheaffer SM, et al. Zika virus infection damages the testes in mice. Nature. 2016;540:438-42.

Griffin BD, Muthumani K, Warner BM, et al. DNA vaccination protects mice against Zika virus-induced damage to the testes. Nat Commun. 2017;8:15743.

Huits RMHG, De Smet B, Ariën KK, et al. Kinetics of Zika virus persistence in semen. Bull World Health Organ. E-pub: 06 Jul 2016. doi: http://dx.doi.org/10.2471/BLT.16.1813 
Joguet G, Mansuy J, Matusali G, Hamdi S, Walschaerts M, Pavili L, Guyomard S, et al. Effect of acute Zika virus infection on sperm and virus clearance in body fluids: A prospective observational study. Lancet Infect Dis. 2017;17:1200-8.

Leung GH, Baird RW, Druce J, Anstey NM. Zika virus infection in Australia following a monkey bite in Indonesia. Southeast Asian J Trop Med Public Health. 2015;46:460-4.

Lovagnini Frutos MG, Ochoa JH, Barbas MG, Lucchini HD, Moya $M$, Malinger $G$. New insights into the natural history of congenital Zika virus syndrome. Fetal Diag Ther. 2018;44(1):72-6.

Ma W, Li S, Ma S, et al. Zika virus causes testis damage and leads to male infertility in mice. Cell. 2016;167:1511-24.

McCarthy M. Zika virus transmitted by sexual contact in Texas, health officials report. BMJ. 2016;352:i720.

Mead P, Duggal N, Hook SA, et al. Zika virus shedding in semen of symptomatic infected men. N Engl J Med. 2018;378(15):1377-85.

Mlakar J, Korva M, Tul N, et al. Zika associated microcephaly. N Eng J Med. 2016;374:951-8.

Moore CA, Staples JE, Dobyns WB, et al. Congenital Zika syndrome: Characterizing the pattern of anomalies for pediatric healthcare providers. JAMA Pediatr. 2017;171(3):288-95.

Moreira EL, Nielsen-Saines K, Brasil P, et al. Neurodevelopment in infant exposed to Zika virus in utero. N Engl J Med. 2018;379:2377_ 9 .

Moreira J, Peixoto TM, Siqueira AM, Lamas CC. Sexually acquired Zika virus: A systematic review. Clin Microbiol Infect. 2017;23: 296-305.

Musso D, Nhan T, Robin E, et al. Potential for Zika virus transmission through blood transfusion demonstrated during an outbreak in French Polynesia, November 2013 to February 2014. Euro Surveill. 2014; 19:20761.

Nicastri E, Castilletti C, Liuzzi G, Iannetta M, Capobianchi MR, Ippolito G. Persistent detection of Zika virus RNA in semen for six months after symptom onset in a traveller returning from Haiti to Italy, February 2016. Euro Surveill. 2016;21(32):doi: 10.2807/1560-7917.ES.2016.21.32.30314.

Oduyebo T, Polen KD, Walke HT, et al. Update: Interim guidance for healthcare providers caring for pregnant women with possible Zika exposure - United States (including US Territories) July 2017. MMRW Morb Mortal Wkly Rep. 2017;66:781-93.

Pan American Health Organization/World Health Organization. Zika suspected and confirmed cases reported by countries and territories in the Americas Cumulative cases, 2015-2017. Updated as of 04 January 2018. Washington, D.C.: PAHO/WHO.

Parra-Saavedra M, Reefhuis J, Piraquive JP, et al. Serial head and brain imaging of 17 fetuses with confirmed Zika virus infection in Colombia, South America. Obstet Gynecol. 2017;130(1):207-12.
Petersen EE, Meaney-Delman D, Neblett-Fanfair R, et al. Update: Interim guidance for preconception couselling and preention of sexual transmission of Zika virus for persons with possible zika virus exposure - United States Sept 2016. MMWR Morb Mortal Wkly Rep. 2016;65:1077-81.

Polen KD, Gilboa SM, Hills S, Oduyebo T, Kohl KS, Brooks JT, Adamski A. Interim guidance for preconception counseling and prevention of sexual transmission of Zika virus for men with possible exposure - United States, August 2018. MMWR Morb Mortal Wkly Rep. Aug 10, 2018;67(31):868-71.

Pomar L, Vouga M, Lambert V, et al. Maternal-fetal transmission and adverse perinatal outcomes in pregnant women infected with Zika virus: Prospective cohort in French Guiana. BMJ. 2018;363: k4431.

Rice ME, Galang RR, Roth NM, et al. Vital signs: Zika-associated birth defects and neurodevelopmental abnormalities possibly associated with congenital Zika virus infection - US Territories and Freely Associated States, 2018. MMWR Morb Mortal Wkly Rep. 2018;67:858-67.

Sanz Cortes M, Rivera AM, Yepez M, et al. Clinical assessment and brain findings in a cohort of mothers, fetuses and infants infected with ZIKA virus. Am J Obstet Gynecol. 2018;218(4):440.e1-440. e36.

Sarno M, Sacramento GA, Khouri R, et al. Zika virus infection and stillbirths: A case of hydrops fetalis, hydranencephaly and fetal demise. PLoS Negl Trop Dis. 2016;10(2):e0004517.

Shapiro-Mendoza CK, Rice ME, Galang RR, et al. Pregnancy outcomes after maternal Zika virus infection during pregnancy - U.S. Territories, January 1,2016-April 25, 2017. MMWR Morb Mortal Wkly Rep. 2017;66(23):615-21.

Shaub B, Vouga M, Najioullah F, et al. Analysis of blood from Zika virus-infected cases: A prospective series. Lancet Infect Dis. 2017;17(5):520-7.

Swaminathan S, Schlaberg R, Lewis J, Hanson KE, Couturier MR. Fatal Zika virus infection with secondary nonsexual transmission. N Engl J Med. 2016;375:1907-9.

Turmel JM, Abgueguen P, Hubert B, Vandamme YM, Maquart M, Le Guillou-Guillemette H, et al. Late sexual transmission of Zika virus related to persistence in the semen. Lancet. 2016;387:2501.

Walker CL, Merriam AA, Ohuma EO, Dighe MK, Gale M, Rajagopal $\mathrm{L}$, et al. Femur-sparing pattern of abnormal fetal growth in pregnant women from New York City after maternal Zika virus infection. Am J Obstet Gynecol. 2018;219(2):187.e1-187.e20. 